\title{
ЭПИЛЕПТОЛОГИЯ
}

УДК 616.853.5:616.89-008.1:616.06:616-08-06

Для цитирования: Казенных Т.В., Бохан Н.А. Психические расстройства при церебральных пароксизмах эпилептического генеза. Сибирский вестник психиатрии и наркологии. 2020; 2 (107): 82-88. https://doi.org/10.26617/1810-3111-2020-2(107)-82-88

\section{Психические расстройства при церебральных пароксизмах эпилептического генеза}

\section{1Казенных Т.В., 1, 2 Бохан Н.А.}

${ }^{1}$ Научно-исследовательский институт психического здоровья, Томский национальный исследовательский медииинский центр Российской академии наук (НИИ психического здоровья Томский НИМЦ)

Россия, 634014, Томск, ул. Алеутская, 4

${ }^{2}$ Сибирский государственный медииинский университет

Россия, 634050, Томск, Московский тракт, 2

\section{PEЗЮME}

Типичным клиническим признаком эпилепсии являются специфические изменения психики. Формирование изменений характера больных эпилепсией обусловлено личностным реагированием на отношение окружающих, осознанием своей болезни и связанных с ней психических дефектов, преморбидными характерологическими особенностями до манифестации эпилепсии. К проявлениям эпилептической болезни относятся эпизодические психозы с расстройствами сознания и психомоторным возбуждением. Нами проведен анализ психических расстройств при пароксизмальных состояниях различного генеза, выполненный на выборке из 1039 больных. Выявлено, что пароксизмальные состояния могут быть как первичными, обусловленными самим психопатологическим процессом; так и вторичными, связанными с влиянием негативных средовых факторов, прежде всего с психогенными воздействиями, а также с побочными действиями лекарственных средств и с осложнениями, вызванными хирургическим лечением. Диагностированные психические расстройства у обследованных пациентов имели четкую пароксизмальную очерченность, различную по клинической наполняемости и временным характеристикам. При этом выраженность расстройств находилась в зависимости от длительности заболевания, представленности неврологической симптоматики и очаговости поражения на МРТ, выраженности коморбидной психопатологической симптоматики, адекватности персонализированных реабилитационных программ.

Ключевые слова: эпилепсия, формирование и динамика психических расстройств, распространенность, психопатологическая и неврологическая симптоматика.

\section{ВВЕДЕНИЕ}

Как указано в определении эпилепсии, вторым характерным клиническим признаком заболевания являются специфические изменения психики. Особенности личности формируются уже на ранних этапах заболевания и прослеживаются на всем его протяжении, включая наиболее поздние его стадии [1, 2, 3, 4]. Наиболее типичными изменениями личности при определенной длительности эпилепсии считается, прежде всего, полярность аффекта в виде сочетания аффективной вязкости, склонности «застревать» на тех или иных, особенно отрицательно окрашенных, аффективных переживаниях, с одной стороны, и аффективной взрывчатости (эксплозивности), импульсивности с большой силой аффективного разряда - c другой, а также эгоцентризм с концентрацией всех интересов на собственных потребностях и желаниях, аккуратность, доходящая до педантизма, гиперболизированное стремление к порядку, ипохондричность, сочетание грубости, агрессивности по отношению к одним и угодливости, подобострастия к другим [5, 6]. Менее специфичными в клинической картине стойких изменений личности при эпилепсии являются нарушения интеллектуально-мнестических функций [7, 8]. Изменения личности носят стадийный характер - в начальной стадии заболевания они отсутствуют либо носят стертый, невыраженный характер. В формировании изменений характера больных эпилепсией определенная роль принадлежит реакциям личности на отношение окружающих, а также на осознание своей болезни и связанных с ней психических дефектов. 
Кроме того, большую роль играют преморбидные особенности характера больного, акцентуация которых происходит задолго до манифестации эпилепсии. К общепринятым проявлениям эпилептической болезни издавна относятся эпизодические психозы с расстройствами сознания и психомоторным возбуждением, частота их колеблется от $7,7 \%$ до $22,3 \%$, причем связана с определенным типом течения болезни $[3,9]$.

\section{ЦЕЛЬ ИССЛЕДОВАНИЯ}

Изучить распространенность и типологические характеристики психических расстройств у пациентов с эпилепсией.

\section{МАТЕРИАЛЫ И МЕТОДЫ}

Проведено описательное исследование психических расстройств у 1039 больных эпилепсией, обратившихся в Эпилептологический кабинет (ЭК) за период 2001-2010 гг. (из них 527 женщин и 512 мужчин), с различной давностью заболевания и различной выраженностью психических расстройств.

Критерии отбора: наличие верифированного диагноза эпилепсии (G40), наличие информированного добровольного согласия на лечение и исследование.

Критерии исключения: эндогенные расстройства, употребление ПАВ, тяжелые декомпенсированные неврологические и соматические заболевания, беременность и кормление грудью, отказ пациента от участия в исследовании.

Основные методы исследования: клиниконеврологический, клинико-психопатологический, клинико-динамический, клиникокатамнестический, экспериментально-психологический (таблицы Шульте, метод пиктограмм, методика незаконченных предложений, проба на переключение), статистический (использован критерий Стьюдента для независимых выборок).

\section{РЕЗУЛЬТАТЫ}

Анализ основных типов эпилептических приступов и оценка наличия объективных неврологических синдромов свидетельствуют, что в $2 / 3$ случаев была диагностирована парциальная эпилепсия, что обусловило представленность психической симптоматики и в целом благоприятное течение болезни.

При анализе психических расстройств в рамках эпилептической болезни мы квалифицировали состояние больных согласно критериям МКБ-10. Состояние «без психических расстройств» диагностировали в $12,4 \%$ случаев: у 79 мужчин $(15,4 \%)$ и 50 женщин $(9,4 \%)$.
Клинические проявления у этих пациентов исчерпывались различными моторными пароксизмами без изменений сознания и вторичной генерализации, а также приступами типа grand mal без изменения личности. Среди пациентов мужского пола чаще встречалось легкое когнитивное расстройство в связи с эпилепсией (F06.72.) и расстройство личности в связи с эпилепсией (F07.02). В 83 случаях состояние больных было отягощено приемом алкоголя, что способствовало более быстрому прогрессированию основного заболевания. Среди женщин достоверно чаще выявлялось органическое эмоционально лабильное (астеническое) расстройство в связи с эпилепсией (F06.62). Клинических случаев коморбидного с эпилепсией психического расстройства у женщин выявлено 30 , среди мужчин - 10 (в целом 3,84\%).

Далее проведен анализ выявленных психических расстройств согласно общепринятой в эпилептологической литературе классификации (Гасто А., 1975).

Предиктальные психические расстройства составили 43 случая (4,1\% от всех больных) 27 мужчин и 16 женщин.

Предиктальные расстройства представлены эпилептическим продромом в виде цефалгий, сенестопатических ощущений, выраженной тревоги, общего психологического дискомфорта. Эпилептический продром у мужчин и женщин диагностирован примерно с одинаковой частотой $(55,6 \%$ и $56,3 \%)$ и в большинстве случаев выражался цефалгиями. Давность заболевания у мужчин составляла не более 5 лет. Как правило, мужчины более чувствительны к изменениям самочувствия, обращая внимание на малейшие изменения состояния. Предиктальные расстройства у женщин были полиморфны, как правило, отмечалось сочетание нескольких психопатологических симптомов, а длительность болезни так же не превышала 5 лет. При цефалгиях больные жаловались на диффузную головную боль без конкретной локализации либо указывали на боли в лобной и лобновисочной областях, по характеру тупую, ноющую, с ощущением тяжести в голове. Продолжительность таких расстройств составляла от нескольких часов до 2 суток, сопровождаясь раздражительностью, отказом от контактов с окружающими, торпидностью в поведении. В случаях, когда в качестве эпилептического продрома выявлялись сенестопатии, тревога или сочетание этих феноменов с цефалгиями, давность заболевания была менее 5 лет. Субъ- 
ективные ощущения пациентов с трудом поддавались точному описанию, ведущим симптомом было тревожное напряжение, сопровождавшееся психологическим дискомфортом с дисфорическим оттенком и телесными сенсациями.

Клинические проявления в структуре $u \kappa-$ тальных психических расстройств были полиморфными. Простые парциальные припадки представлены разными видами ауры в традиционном понимании, за которыми не следовали генерализованные приступы. Чаще встречались вегетативно-висцеральные проявления, сопровождающиеся вегетативным компонентом и кардиальными, эпигастральными, абдоминальными ощущениями (у 13,1\% всех пациентов с верифицированным диагнозом G40.1). Кроме того, отмечались простые парциальные сенсорные обонятельные припадки, во время которых больные ощущали разнообразные запахи, например, роз или бензина (3,6\%). Чувство беспричинного подъема настроения, страха, тревоги, дисфории, расцененные нами как простые парциальные припадки с психическими (аффективными) нарушениями, были диагностированы у 2,2\% пациентов. К простым парциальным припадкам отнесены так же припадки с нарушением психических функций в форме дисмнестических расстройств (deja vu, jamai vu и др.), других их разновидностей не наблюдалось. Давность заболевания у преобладающего числа больных $(83,9 \%)$ с простыми парциальными припадками составляла 5-10 лет. Сложные парциальные припадки, протекавшие с изменением сознания и сопровождавшиеся разнообразными вегетативными и психопатологическими проявлениями, имели место у 7,2\% пациентов. Практически в половине случаев (445 чел. - 42,8\%) отмечалась вторичная генерализация. В подавляющем большинстве случаев генерализованные тонико-клонические приступы развивались вслед за простыми парциальными припадками. К первично генерализованным припадкам с психическими расстройствами мы отнесли различные варианты типичных абсансов. Во многих случаях в оба периода абсансы сочетались с припадками petit mal по типу атонических, миоклонических приступов, а также приступами типа grand mal. Таких первично генерализованных полиморфных по своим клиническим проявлениям случаев было более 70\%, в остальных случаях - генерализованные однотипные приступы.
Удельный вес пациентов мужского и женского пола с приступами со вторичной генерализацией оказался приблизительно равным. Первично генерализованные приступы, сопровождающиеся психическими расстройствами, достоверно чаще отмечались у больных мужского пола. Возрастная характеристика пациентов мужского и женского пола, у которых были выявлены иктальные психические расстройства, не отличалась при сопоставлении данных: более 75\% больных были в возрасте 16-45 лет.

Постиктальные психические расстройства выражались длительным восстановлением ясности сознания, сумеречными расстройствами сознания, которые развивались непосредственно вслед за приступами типа grand mal после восстановления сознания в интервале от нескольких часов до 7 дней. Подобные феномены отмечались только у 20 больных (1,9\% от всех больных ЭК с эпилепсией) с давностью заболевания более 5 лет. Постиктальные психические расстройства с одинаковой частотой встречались у пациентов женского и мужского пола. Возрастная характеристика пациентов с постиктальными расстройствами психической деятельности отличается от того, что было отмечено при анализе иктальных расстройств все пациенты были старше 15 лет.

Интериктальные психические расстройства (специфические расстройства личности), выявленные у 870 пациентов (83,7\%), 423 мужчин и 447 женщин, представлены специфическими изменениями личности (глишроидия) разной степени выраженности. Достоверно чаще (35,3\% больных эпилепсией) зафиксировано органическое астеническое расстройство в связи с основным заболеванием (F06.62), что клинически проявлялось быстрой утомляемостью, истощаемостью психической деятельности, нарушением концентрации внимания, гиперестезией, усталостью в конце беседы, эмоциональной лабильностью, расстройством памяти и сна по астеническому типу. Легкое когнитивное расстройство в связи с эпилепсией (F06.72), диагностированное у 257 пациентов (24,7\%), представлено нарушениями когнитивных функций. Снижение когнитивной продуктивности проявлялось в сферах памяти, мышления, речи, поведения: в памяти - в виде сложности запоминания и воспроизведения нового материала, в мышлении - в затруднении формулировки общих и абстрактных идей, в речи в трудностях поиска слов, в поведении - в некоторой растерянности и аффекте недоумения. 
Экспериментально-психологические исследования выявили тугоподвижность и замедленность мышления, легкую степень олигофазии. При прогредиентном (безремиссионном) типе течения заболевания выявлены выраженные личностные расстройства. У большинства больных когнитивные и эмоционально-волевые нарушения проявлялись одинаково: стойкое снижение памяти, медленное обстоятельное вязкое мышление, выраженная олигофазия и типичная характеропатия с поведенческими трудностями в виде крайней обидчивости, раздражительности, конфликтности, агрессивности. Нередко имело место сочетание отрицательных черт: эгоцентризм, жадность, неискренность, лживость, слащавость, стойкое негативное отношение к ближайшим родственникам, что затрудняло адаптацию пациентов в семье и в обществе. В соответствии с МКБ-10 данная симптоматика у 226 человек $(21,8 \%)$ соответствовала расстройствам личности в связи с эпилепсией (F07.02).

Далее была изучена структура выявленных интериктальных расстройств среди пациентов мужского и женского пола. Сравнение экстенсивных показателей, рассчитанных отдельно для больных мужского и женского пола, выявило достоверные различия, которые можно интерпретировать следующим образом: интериктальные расстройства легкой степени чаще встречались у мужчин, чем у женщин. Выявлены достоверные различия в распространенности расстройств в рамках рубрик F06.62 и F07.2: удельный вес выраженных расстройств личности был выше у больных мужского пола (26,9\% против $16,9 \%)$, в то время как органических астенических расстройств - у лиц женского пола (45,3\% против $25,0 \%)$. Возрастная характеристика пациентов с интериктальными психическими расстройствами не выявила достоверных отличий.

Изучение возрастного распределения различных видов психических расстройств показало, что предиктальные психические расстройства чаще встречаются у больных в возрасте до 15 лет, в то время как постиктальные предпочтительны для лиц более старшего возраста. По мере увеличения возраста больных эпилепсией растет удельный вес интериктальных психических расстройств.

Проанализированы случаи, когда причиной болезни было злоупотребление спиртными напитками или лекарственными препаратами, точнее, наркосодержащими веществами $(7,9 \%$ от общего числа пациентов, страдающих эпилептической болезнью). Данный показатель оказался меньше, чем было обнаружено при изучении микста шизофрении и алкоголизма, где удельный вес сочетанной патологии достигал 27\% [10]. Однако в отличие от сочетания шизофрении с алкоголизмом микст алкоголизма или психоактивных веществ с эпилепсией обусловливает усугубление типичной клинической симптоматики (учащение и большую выраженность пароксизмальных расстройств, изменение личности по органическому типу), а также психотические расстройства, соответствующие по клинической картине экзогенным психозам.

Синдромально среди выявленных психических расстройств преобладали расстройства когнитивной сферы. При патопсихологическом обследовании пациентов были выявлены характерные изменения мышления, памяти, личностные расстройства. Когнитивное снижение в той или иной степени было диагностировано нами в $83,8 \%$ случаев. У больных, наряду с явлениями общей брадикинезии, отмечалось изменение темпа психических процессов, что наглядно проиллюстрировано результатами исследования таблицами Шульте. Большинство респондентов затрачивали на поиск чисел в одной таблице от 45 секунд до 2-3 минут. Даже при небольшой давности заболевания (от 1 до 3 лет) происходили изменения подвижности психических процессов, что подтверждалось пробой на переключение. 956 (92\%) испытуемых допускали ошибки чередования при попеременном прибавлении к заданному числу двух других. Инертность, вязкость мышления больных эпилепсией отчетливо проявлялись в словесном эксперименте, о чем свидетельствовали увеличение латентного периода, частые эхолалические реакции, однообразное повторение одних и тех же ответов. Часто на словараздражители респонденты называли стереотипные ряды слов или термины профессионального обихода, включали себя в ситуацию, которую описывали, что расценивалось нами как преобладание конкретных представлений в мышлении больных эпилепсией, недостаточность в осмыслении условного характера задания как проявление эгоцентрических тенденций. Аналогичное включение себя в ситуацию отмечалось и в пиктограммах пациентов. Даже в обычной беседе больные демонстрировали склонность к чрезмерной детализации, обстоятельности. 
Выполняя рисуночные тесты, пациенты фиксировались на незначительных деталях, затруднялись в выделении существенных признаков явлений и предметов, при этом иногда отходя от общего смысла рисунка, что свидетельствовало о снижении уровня процессов обобщения и отвлечения. Последующее припоминание демонстрировало снижение кратковременной памяти. Кривая запоминания более чем у половины испытуемых $(675$ - 64,9\%) отличалась своеобразностью - количество воспроизводимых слов с каждым последующим повторением либо незначительно увеличивалось, либо оставалось прежним. При более глубоких нарушениях памяти кривая запоминания носила более пологий характер.

Личностные особенности в том числе изучались и посредством методики незаконченных предложений. Полученные при этом данные позволили охарактеризовать систему личностных отношений респондентов. На первый план выступало значительное преобладание словесных импунитивных реакций, отражающих тенденцию к нивелированию возможных конфликтных факторов. В других случаях, напротив, при усилении фрустрирующих факторов первое место занимал другой компонент аффективной пропорции - взрывчатость, злобность, что особенно явно проявлялось в психическом статусе пациентов с аффективными расстройствами.

Необходимо отметить, что выраженность когнитивных нарушений находилась в четкой зависимости от длительности заболевания, представленности неврологической симптоматики и очаговости поражения на МРТ, адекватности реабилитационных мероприятий.

Вторыми по частоте встречаемости в структуре психических расстройств у больных эпилепсией явились расстройства аффективной сферы $(59,4 \%)$ в виде раздражительности, сниженного настроения, эмоциональной лабильности, склонности к реакциям тревоги. Понижению настроения у больных сопутствовали чувство тоски, склонность к слабодушным реакциям. Отмечалось обилие «соматических» жалоб: различные по характеру и интенсивности головные боли, чувство разбитости, неприятные ощущения в различных частях тела, общая слабость организма. Более чем в 3 раза реже $(18,2 \%)$ встречались случаи сниженного настроения с дисфорией и тревогой, сопровождавшиеся вспыльчивостью, обидчивостью, плаксивостью.
У 7 больных (6,9\%) причиной становления депрессии служил психогенный запуск, для 4 из них безусловным травмирующим фактором оказалось установление диагноза эпилепсии, для остальных актуальной психогенией стал разрыв отношений со значимым близким. При этом у 1 больной были выявлены суицидальные высказывания, в связи с чем она была госпитализирована в психиатрический стационар. Депрессивное настроение, тревога и беспокойство в таких случаях были причинно обусловлены. Согласно МКБ-10, состояние этих пациентов диагностировалось как депрессивная реакция в связи с расстройством адаптации. Астенический синдром у больных эпилепсией с психическими расстройствами отмечался более чем у трети $(35,3 \%)$ пациентов, при этом достоверно чаще зарегистрирован верифицированный вариант с преобладанием вегетативных нарушений, что являлось особенностью психических нарушений, коморбидных с органической патологией. В единичных случаях в качестве основной психопатологической симптоматики выступали галлюцинаторно-бредовые расстройства $(2,1 \%)$.

\section{ВЫВОДЫ}

Анализ клинического течения психических расстройств, ассоциированных с пароксизмальными состояниями различного генеза, свидетельствует, что они могут быть как первичными, обусловленными самим психопатологическим процессом, так и вторичными, связанными с влиянием негативных средовых факторов, прежде всего с психогенными воздействиями (различными по длительности и интенсивности), а также с побочным действием лекарственных средств и с осложнениями, вызванными хирургическим лечением. Выявленные психические расстройства имели четкую пароксизмальную очерченность, различную по клинической наполняемости и временным характеристикам. При этом выраженность психических нарушений находилась в отчетливой зависимости от длительности заболевания, представленности неврологической симптоматики и очаговости поражения по результатам МРТ-диагностики, выраженности коморбидной психопатологической симптоматики, адекватности персонализированного комплекса реабилитационных мероприятий.

\section{КОНФЛИКТ ИНТЕРЕСОВ}

Авторы заявляют об отсутствии явных и потенциальных конфликтов интересов в связи с публикацией данной статьи. 


\section{ИСТОЧНИК ФИНАНСИРОВАНИЯ}

Исследование выполнено в рамках комплексной темы НИР «Комплексное исследование клинико-психопатологических закономерностей и патобиологических механизмов формирования и прогредиентности социально значимых психических и поведенческих расстройств с разработкой инновационных методов ранней диагностики, персонализированных стратегий терапии и профилактики» (номер госрегистрации АААА-А19-119020690013-2 государственного задания № 075-01412-20-03).

\section{СООТВЕТСТВИЕ ПРИНЦИПАМ ЭТИКИ}

Исследование было проведено с соблюдением норм современной биомедицинской этики и этических стандартов, разработанных в соответствии с Хельсинской декларацией ВМА (протокол заседания этического комитета НИИ психического здоровья Томского НИМЦ № 133/2.2020 от 19.06.2020 г.).

ЛИТЕРАТУРА

1. Болдырев А.И. Психические изменения в развернутой стадии эпилепсии. Российский психиатрический журнал. 2001; 1: 10-13.

2. Карлов В.А. Пароксизмальный мозг: клинические и нейрофизиологические аспекты. Эпилепсия и пароксизмальные состояния. 2015; 7 (4): 9-15. DOI: 10.17749/2077-8333.2015.7.4.009-015

3. Казаковцев Б.А. Психические расстройства при эпилепсии. Изд. 2-е, испр. и доп. М.: ООО «Издательство Прометей», 2015: 444.

4. Громов С.А., Якунина О.Н. Непсихотические психические расстройства и изменения личности на начальных стадиях эпилепсии (клинико- психологическое исследование). Эпилепсия и пароксизмальные состояния. 2015; 2: 18-24. DOI: 10.17749/2077-8333.2015.7.2.018-024

5. Михайлов В.А., Дружинин А.К., Липатова Л.В., Киссин М.Я., Бочаров В.В. Непсихотические психические расстройства у больных эпилепсией пожилого возраста и их влияние на качество жизни. Обозрение психиатрии и медицинской психологии им. В.М. Бехтерева. 2015; 2: 59-66.

6. Карлов В.А. Развивающийся, инволюционирующий мозг, цереброваскулярные заболевания и эпилепсия. Журнал неврологии и психиатрии им. С.С. Корсакова. 2009;109(3):4-7.

7. Лекомцев В.Т. Когнитивные расстройства при эпилепсии. Восточно-Европейский научный вестник. 2015; 3-4: 17-19.

8. Костылев А.А, Пизова Н.В., Пизов Н.А. Когнитивные нарушения при эпилепсии. Неврология, нейропсихиатрия, психосоматика. 2013; 4: 6670. DOI: http://dx.doi.org/10.14412/2074-27112013-2458

9. Железнова Е.В., Токарева Н.Г. Клиникопсихологические характеристики расстройств функционирования при эпилепсии. Российский психиатрический журнал. 2017; 3: 27-32.

10. Уманская П.С., Агарков А.П., Агарков А.А. Формирование и течение алкоголизма, особенности суицидального поведения у лиц, перенесших алкогольный психоз (гендерный аспект). Обозрение психиатрии и медиичиской психологии им. В.М. Бехтерева. 2018; 3: 71-79. DOI: $10.31363 / 2313-7053-2018-3-71-79$

Поступила в редакцию 20.02.2020 Утверждена к печати 01.06.2020

Казенных Татьяна Валентиновна, кандидат медицинских наук, ученый секретарь НИИ психического здоровья. Researcher ID J-1673-2017. Author ID Scopus 57195285544. Author ID РИНЦ 626033. SРIN-код РИНЦ 6956-3031.

Бохан Николай Александрович, академик РАН, д.м.н., профессор, заслуженный деятель науки РФ, руководитель отделения аддиктивных состояний, директор НИИ психического здоровья, заведующий кафедрой психиатрии, наркологии и психотерапии ФГБОУ ВО СибГМУ Минздрава России. Author ID Scopus 6506895310. ORCID ID 0000-0002-1052-855X. Researcher ID P-1720-2014. Author ID РИНЦ 152392. SРIN-код РИНЦ 2419-1263.

Казенных Татьяна Валентиновна, kazennyh@sibmail.com

UDC 616.853.5:616.89-008.1:616.06:616-08-06

For citation: Kazennykh T.V., Bokhan N.A. Mental disorders in cerebral paroxysms of epileptic origin. Siberian Herald of Psychiatry and Addiction Psychiatry. 2020; 2 (107): 82-88. https://doi.org/10.26617/1810-3111-2020-2(107)-82-88

\title{
Mental disorders in cerebral paroxysms of epileptic origin
}

\section{Kazennykh T.V., 1, 2Bokhan N.A.}

\author{
${ }^{1}$ Mental Health Research Institute, Tomsk National Research Medical Center, Russian Academy of Sciences \\ Aleutskaya Street 4, 634014, Tomsk, Russian Federation \\ ${ }^{2}$ Siberian State Medical University \\ Moskovsky Trakt 2, 634050, Tomsk, Russian Federation
}




\section{ABSTRACT}

A typical clinical sign of epilepsy are specific changes in the psyche. The formation of changes in the nature of patients with epilepsy is due to a personal response to the attitude of others, awareness of their illness and related mental defects, premorbid characterological features before the manifestation of epilepsy. The manifestations of epileptic disease include episodic psychoses with impaired consciousness and psychomotor agitation. We conducted an analysis of mental disorders in paroxysmal conditions of various origins, performed on a sample of 1,039 patients. It was revealed that paroxysmal conditions can be as primary, due to the psychopathological process itself; and secondary, associated with the influence of negative environmental factors, primarily with psychogenic effects, as well as with side effects of drugs and with complications caused by surgical treatment. Diagnosed mental disorders in the examined patients had a clear paroxysmal outline, different in clinical filling and temporal characteristics. Moreover, the severity of the disorder was dependent on the duration of the disease, the presentation of neurological symptoms and the focal lesion on MRI, the severity of comorbid psychopathological symptoms, and the adequacy of personalized rehabilitation programs.

Keywords: epilepsy, the formation and dynamics of mental disorders, prevalence, psychopathological and neurological symptoms.

\section{REFERENCES}

1. Boldyrev A.I. Mental changes in the advanced stage of epilepsy. Russian Psychiatric Journal. 2001; 1: 10-13 (in Russian).

2. Karlov V.A. Paroxysmal brain: clinical and neurophysiological aspects. Epilepsy and Paroxysmal Conditions. 2015; 7 (4): 9-15 (in Russian). DOI: 10.17749/2077-8333.2015.7.4.009-015

3. Kazakovtsev B.A. Mental disorders in epilepsy. 2nd edition, revised and supplemented. Moscow: Prometey Publishing House, 2015: 444 (in Russian).

4. Gromov S.A., Yakunina O.N. Non-psychotic psychiatric disorders and personality changes in the initial stages of epilepsy (clinical and psychological study). Epilepsy and Paroxysmal Conditions. 2015; 2: 18-24 (in Russian). DOI: $10.17749 / 2077$ 8333.2015.7.2.018-024

5. Mikhailov V.A., Druzhinin A.K., Lipatova L.V., Kissin M.Ya., Bocharov V.V. Non-psychotic psychiatric disorders in elderly patients with epilepsy and their impact on quality of life. Bekhterev Review of Psychiatry and Medical Psychology. 2015; 2: 59-66 (in Russian).
6. Karlov V.A. Evolving, involving brain, cerebrovascular disease, and epilepsy. S.S. Korsakov Journal of Neurology and Psychiatry. 2009;109(3):4-7(in Russian).

7. Lekomtsev V.T. Cognitive disorders in epilepsy. East European Scientific Herald. 2015; 3-4: 17-19 (in Russian).

8. Kostylev A.A., Pizova N.V., Pizov N.A. Cognitive impairment in epilepsy. Neurology, Neuropsychiatry, Psychosomatics. 2013; 4: 66-70 (in Russian). DOI: http://dx.doi.org/10.14412/2074-2711-20132458

9. Zheleznova E.V., Tokareva N.G. Clinical and psychological characteristics of functional disorders in epilepsy. Russian Psychiatric Journal. 2017; 3: 2732 (in Russian).

10. Umanskaya P.S., Agarkov A.P., Agarkov A.A. The formation and course of alcoholism, especially suicidal behavior in people who have undergone alcoholic psychosis (gender aspect). Bekhterev Review of Psychiatry and Medical Psychology. 2018; 3: 7179 (in Russian). DOI: 10.31363/2313-7053-20183-71-79

Received February 20.2020

Accepted June 01.2020

Kazennykh Tatyana V., PhD, Academic Secretary, Mental Health Research Institute, Tomsk National Research Medical Center, Russian Academy of Sciences, Tomsk, Russian Federation. Researcher ID J-1673-2017. Author ID Scopus 57195285544. Author ID RSCI 626033. SPIN-код RSCI 6956-3031

Bokhan Nikolay A., academician of RAS, MD, Professor, Honored Scientist of the Russian Federation, Head of Addictive States Department, director of Mental Health Research Institute, Tomsk National Research Medical Center, Russian Academy of Sciences; Head of the Department of Psychiatry, Addiction Psychiatry and Psychotherapy, Siberian State Medical University, Tomsk, Russian Federation. Author ID Scopus 6506895310. ORCID ID 0000-00021052-855X. Researcher ID P-1720-2014. Author ID RSCI 152392. SPIN-код RSCI 2419-1263.

Kazennykh Tatyana V., kazennyh@sibmail.com 